\title{
Evaluation of the Antidepressant Activity of Griffonia simplicifolia Aqueous Extracts
}

\author{
Bakou Niangoran François ${ }^{1^{*}}$, BA Abdoulaye ${ }^{2}$, Diabate $D^{2}$, Atayi $E^{3}$ \\ ${ }^{1}$ Unit of Animal Physiology, Jean Lorougnon GUEDE University, Daloa, (Côte d'Ivoire) \\ ${ }^{2}$ Laboratory of Neuroscience, UFR Bioscences, Felix HOUPHOUET-BOIGNY University, Abidjan, (Côte d'Ivoire) \\ ${ }^{3}$ Neurology Service, Functional Exploration Unit of the Nervous System, C.H.U. from Cocody-Abidjan, (Côte d'Ivoire)
}

DOI: $10.36348 /$ sijtcm.2020.v03i06.003 $\quad$ | Received: 19.06 .2020 | Accepted: 26.06.2020 | Published: 30.06 .2020

*Corresponding author: Bakou Niangoran François

\section{Abstract}

Objective: The present study was designed to evaluate the acute and chronic behavioral and antidepressant effects of aqueous extracts of $G S$ leaves in standardized rats models of depression. Materials and Methods: Aqueous extracts of $G S$ leaves were prepared, and phytoconstituents were determined using appropriate chemical analytical methods. Animals were divided into five groups: The control group received vehicle (saline water $10 \mathrm{ml} / \mathrm{rat})$. Amitriptyline $(20 \mathrm{mg} / \mathrm{kg} \mathrm{b.w.,}$ IP) was used as the positive control or standard group while the treated rats received $G S(100,200$, and 400mg/kg body weight i.p). In the acute treatment study, a single dose was administered 30 min prior to testing. For the chronic treatment study, a single dose was administered daily for 14 days. In the chronic dose study, the behaviors of all groups were assessed for antidepressant activity $30 \mathrm{~min}$ after the last treatment dose on the $14^{\text {th }}$ day. Different standardized depression models were used for behavioral tests to evaluate the antidepressant activity, such as forced swim test (FST), and tail suspension test (TST) test. Results: The preliminary pharmacological screening with acute dosing exhibited the antidepressant activity of $G S$, but its antidepressant activity was more enhanced after repeated dosing. In comparison with the acute studies, chronic dose studies displayed a significant antidepressant manifestation in the behavioral patterns when compared to the vehicle controls. Conclusion: The results obtained in this study suggest that aqueous extracts of $G S$ may possess an antidepressant activity.

Keywords: Griffonia simplicifolia, leaves, antidepressant activity.

Copyright @ 2020: This is an open-access article distributed under the terms of the Creative Commons Attribution license which permits unrestricted use, distribution, and reproduction in any medium for non-commercial use (NonCommercial, or CC-BY-NC) provided the original author and source are credited.

\section{INTRODUCTION}

Depression has become a wide spread mental disorder worldwide. According to global depression statistics, it is estimated that about 121 million people suffer from mental disorders. Currently, $12.3 \%$ of world population suffer from depression, and it is predicted that by 2020 , the number may rise to $15 \%$.[1] Due to the high cost of antidepressant synthetic drugs and their accompanying side effects, the discovery of safer antidepressant herbal remedies is on the rise. The legume plant Griffonia simplicifolia Baill. (Caesalpiniaceae) is a perennial woody shrub which grows in the tropical rain forest of West and Central Africa, with sites of cultivation present in Ghana, Ivory Coast, and Togo. The seed chemical constituents, including lectins, 5-hydroxy-L-tryptophan (5-HTP), and fatty acids have been studied intensively since 1960 $[1,2]$, whereas leaves may contain lectin II-a legume lectin with GlcNAc binding specificity resulting in insecticidal activity [3]. Seed extracts from $G$. simplicifolia are rich in 5-HTP [4] - a direct precursor and enhancer of the activity of the brain hormone serotonin (5-hydroxytryptamine, 5-HT). After entering the central nervous system, 5-HTP is converted to 5-HT by the enzyme tryptophan decarboxylase [5]. The administration of 5-HTP to animals increases 5-HT levels in the central nervous system (CNS) [6]; however, in humans 5-HTP stimulates 5-HT receptors in the CNS only after conversion to 5-HT [7]. A medical food formulation comprised of G. simplicifolia containing high concentrations of 5-HTP is thought to be effective for serotonin-related disorders [8,9], including depression [10] and young subjects with high levels of romantic stress [11]. Further uses of $G$. simplicifolia seed extracts include the treatment of insomnia, migraine, headache, and the regulation of appetite leading to weight reduction in obese patients, as well as the regulation of mood, memory, and many other functions $[12,13]$. No scientific report regarding the in vivo antidepressant activity of G. simplicifolia 
extract has been published. That's why, the present study was undertaken to assess the possible antidepressant effects following single administration of seed extract from $G$. simplicifolia in rat. For this purpose, we used the forced swim test (FST) and the tail suspension test (TST).

\section{MATERIALS AND METHODS \\ Plant Material}

Seeds from $G$. simplicifolia plant were collected from Daloa, (Cote d'Ivoire) in October, 2019. The plant was identified and verified by botanist Professor from Jean Lorougnon GUEDE university of Daloa (Cote d'ivoire). The collected seeds were dried under a shade during two weeks and pulverized using the crushing assistance (IKAMAG RCT®). The powder of seeds obtained, constituted our sample to be analyzed.

\section{Extract Preparation}

The powder of Seeds from G. simplicifolia was used to prepare the various extracts. Fifty (50) grams of the powder were extracted in $1 \mathrm{~L}$ of distilled water. The mixture obtained was then homogenized using a Mixor during 24 hours. The homogenate obtained is filtered successively twice on absorbent cotton then once on Wattman $\mathrm{N}^{\circ} 1$ filter paper. The filtrate was carried thereafter to evaporation in a drying oven with $50^{\circ} \mathrm{C}$ during 48 hours. We obtained this way a powder which constituted the aqueous total extract used for the preparation of the various products concentrations.

\section{Animals}

25 males Wistar rats aged 8-10 weeks weighing (145 - $250 \mathrm{~g})$ were obtained from the animal house of Jean Lorougnon GUEDE University, Daloa. These animals were housed under standard environmental conditions. The rats were fed with FACI ${ }^{\circledR}$ (Fabrication d'Aliments de Côte d'Ivoire) pellets, groundnuts and dried fish. They had free access to drinking water ad libitum.

\section{Drugs and chemicals}

The standard drugs amitriptyline and saline water were collected from Square Pharmaceuticals Ltd., Cote d'Ivoire. Distilled water which was used for dilution purpose was prepared was obtained from Jean Lorougnon GUEDE university of Daloa (Cote d'Ivoire).

\section{Behavioral parameters used to test antidepressant activity \\ Forced Swim Test}

The procedures for the FST, a widely used behavioral test for the detection of antidepressant-like effects, were similar to those described earlier [14, 15]. Animals were initially placed individually to swim in plastic cylinders $(30 \mathrm{~cm}$ of diameter by $40 \mathrm{~cm}$ in height containing $25 \mathrm{~cm}$ of water at $24 \pm 1^{\circ} \mathrm{C}$ [14] for $15 \mathrm{~min}$ (pretest). They were then removed and allowed to dry in a separate cage before returning to their home cages. Twenty-four hours later the animals were submitted to a 5 min session of forced swimming session (test). During this session the total amount of time in which animals remained immobile (except for small limb movements necessary for floating) were recorded by an observer that was blind to the treatments. The water was changed after each trial to avoid the influence of alarm substances.

\section{Tail suspension test}

TST was carried out according to the method described by Porsolt et al., [16, 17]. Briefly, rats were suspended by their tails using an elastic band attached to the tails by adhesive tape, and the elastic band was hooked onto a horizontal rod. The distance between the tip of the nose of the rat and the floor was approximately $20 \mathrm{~cm}$. The mice were suspended for a period of $5 \mathrm{~min}$, and the time spent immobile during the last $4 \mathrm{~min}$ of the $5 \mathrm{~min}$ was recorded for each individual, by an observer blinded to the genotype.

\section{Experimental Study Design}

Twenty-five rats were randomly divided into five groups (5 rats/group). The control group received vehicle (saline water $10 \mathrm{~mL} / \mathrm{rat}$ ). Amitriptyline $(20 \mathrm{mg} / \mathrm{kg}$ b.w., IP) was used as the positive control or standard group while the treated rats received GS (100, 200 , and $400 \mathrm{mg} / \mathrm{kg}$ body weight i.p). In the acute treatment study, a single dose was administered $30 \mathrm{~min}$ prior to testing. For the chronic treatment study, a single dose was administered daily for 14 days. In the chronic dose study, the behaviors of all groups were assessed for antidepressant activity $30 \mathrm{~min}$ after the last treatment dose on the $14^{\text {th }}$ day. Different standardized depression models were used for behavioral tests to evaluate the antidepressant activity, such as forced swim test (FST), and tail suspension test (TST) test. The groups assigned for acute and chronic dose study were as follows: Group 1: Control group (saline water); Group 2: amitriptyline (20mg/kg); Group 3: GS-1 $(100 \mathrm{mg} / \mathrm{kg})$; Group 4: GS-2 (200mg/kg); Group 5: GS$3(400 \mathrm{mg} / \mathrm{kg})$.

\section{Statistical Analysis}

The differences between experimental and control groups were determined using the statistica 10.0 software for windows. Comparisons among different groups were performed by analysis of variance test. Statistically significant differences between control and experimental groups were assessed by Student's $t$-test. All data are expressed as mean \pm standard error of mean. $P<0.05$ was considered to be significant.

\section{RESULTS}

\section{Acute treatment study}

\section{Forced Swim Test}

The results indicated that after $30 \mathrm{~min}$ administration of $G S 100 \mathrm{mg} / \mathrm{kg}$, there was no 
significant decrease in the immobility time, but both Amitriptyline and test substance treated animals (GS $200 \mathrm{mg} / \mathrm{kg}$ and $G S 400 \mathrm{mg} / \mathrm{kg}$ ) showed slight reductions in immobility time compared to the vehicle controls (Figure-1).

\section{Tail Suspension Test}

No decrease in the immobility time was observed after administering $100 \mathrm{mg} / \mathrm{kg} G S$, whereas the immobility time was markedly shortened in 200 $\mathrm{mg} / \mathrm{kg} G S$ treated animals. Significant reductions in the immobility time were also noted in $400 \mathrm{mg} / \mathrm{kg} G S$ treated animals in comparison with the vehicle control (Figure-2).

\section{Chronic treatment study \\ Forced Swim Test}

In the chronic investigation, results summarized in (Figure-3) show that intraperitoneal administration of aqueous extracts of $G S$ at $100 \mathrm{mg} / \mathrm{kg}$, $200 \mathrm{mg} / \mathrm{kg}$, and $400 \mathrm{mg} / \mathrm{kg}$ caused reductions in FST immobility time in rats. Standard amitriptyline dose of $20 \mathrm{mg} / \mathrm{kg}$ displayed a significant decrease in the immobility time.

\section{Tail Suspension Test}

Results of the 14 days chronic study revealed that there was an inverse relationship between the dose of the extract and the immobility time, that is, an increase in the $G S$ dose produced a corresponding reduction in the immobility time in comparison with the control group (Figure-4). In addition, repeated administration of standard fluoxetine $(20 \mathrm{mg} / \mathrm{kg} / \mathrm{day})$ showed a profound decrease in the mean immobility period. Overall, 14 days repeated administration of $G S$ showed a significant decrease in the immobility activity in both FST and TST animal models.

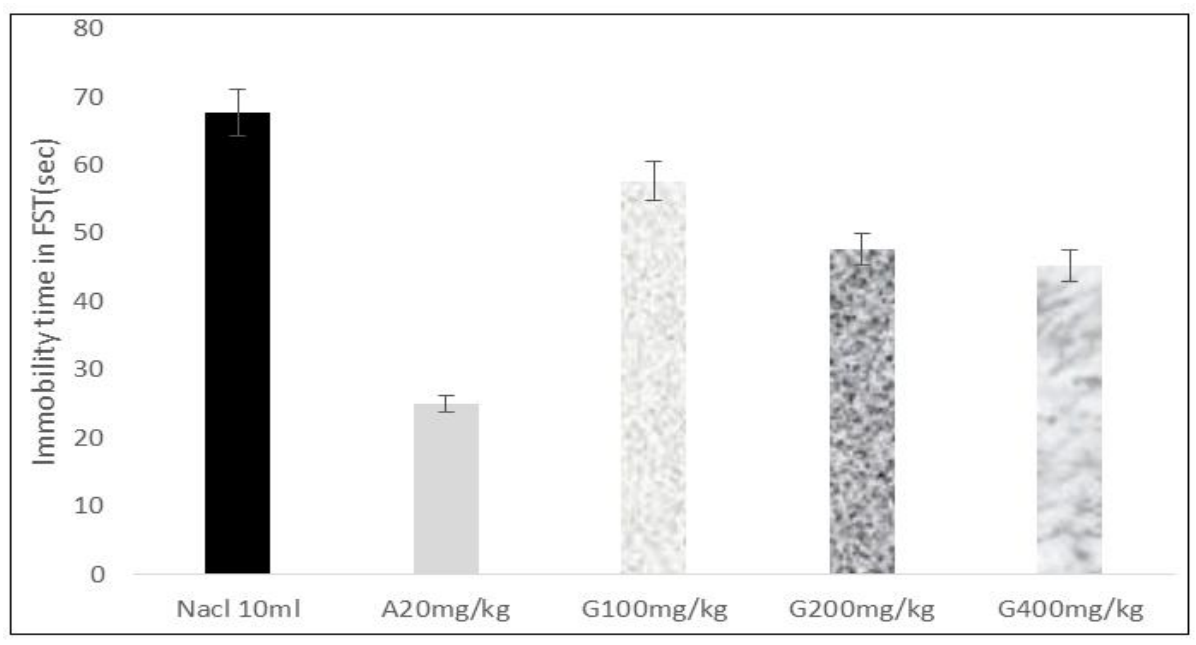

Fig-1: Effet of G. simplicifolia extract on duration of immobility forced swim test

Group 1: Control group (saline water); **Group 2: amitriptyline (20mg/kg); Group 3: GS-1 (100mg/kg); Group 4: GS-2 $(200 \mathrm{mg} / \mathrm{kg})$; Group 5: GS-3 (400mg/kg). Results are represented as mean \pm standard error of mean significantly different at $* \mathrm{P}<0.05$ and $* * \mathrm{P}<0.01$ compared to vehicle control.

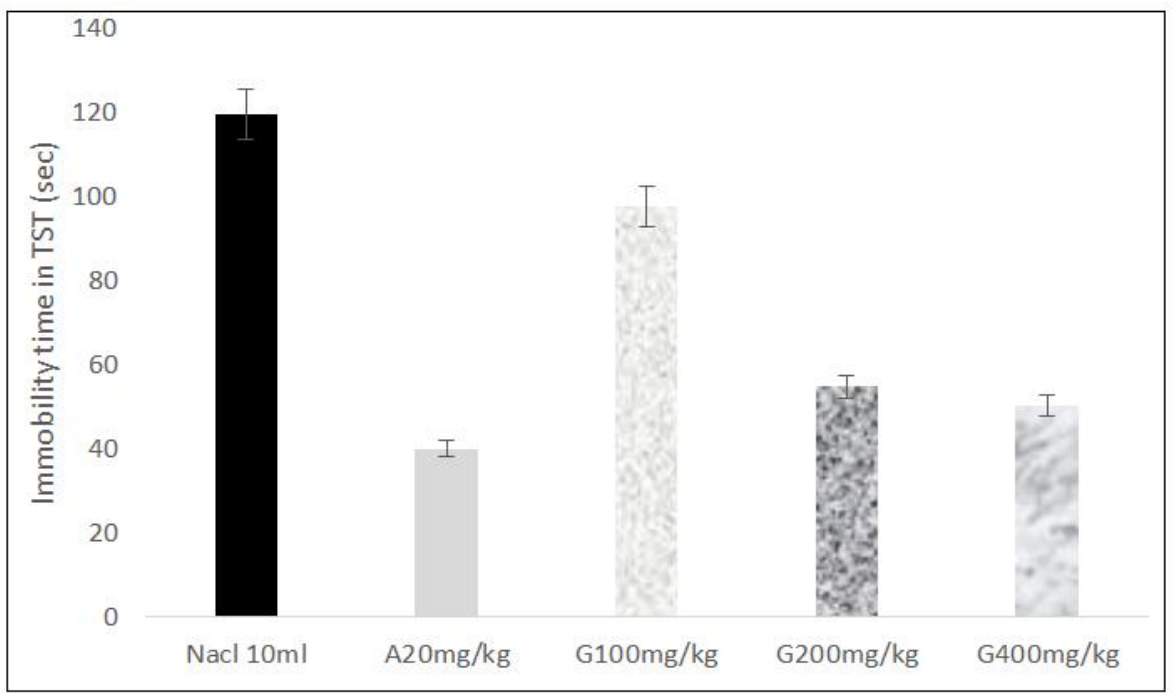

Fig-2: Effet of $G$. simplicifolia extract on duration of immobility in tail suspension test 
Group 1: Control group (saline water); **Group 2: amitriptyline (20mg/kg); Group 3: GS-1 (100mg/kg); **Group 4: GS$2(200 \mathrm{mg} / \mathrm{kg}) ; * *$ Group 5: GS-3 $(400 \mathrm{mg} / \mathrm{kg})$. Results are represented as mean \pm standard error of mean significantly different at $* \mathrm{P}<0.05$ and $* * \mathrm{P}<0.01$ compared to vehicle control.

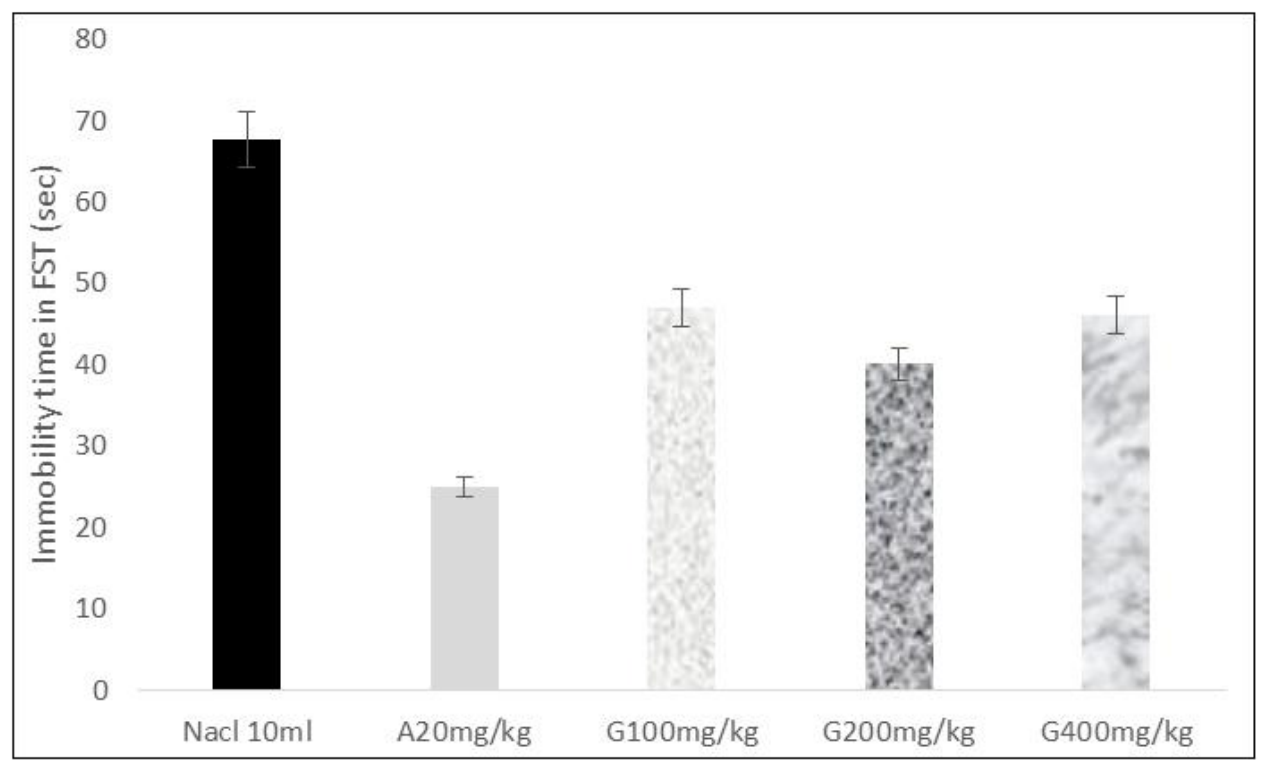

Fig-3: Effet of chronic administration of $G$. simplicifolia extract on duration of immobility forced swim test

Group 1: Control group (saline water); **Group 2: amitriptyline (20mg/kg); *Group 3: GS-1 (100mg/kg); **Group 4: GS-2 (200mg/kg); *Group 5: GS-3 (400mg/kg). Results are represented as mean \pm standard error of mean significantly different at $* \mathrm{P}<0.05$ and $* * \mathrm{P}<0.01$ compared to vehicle control.

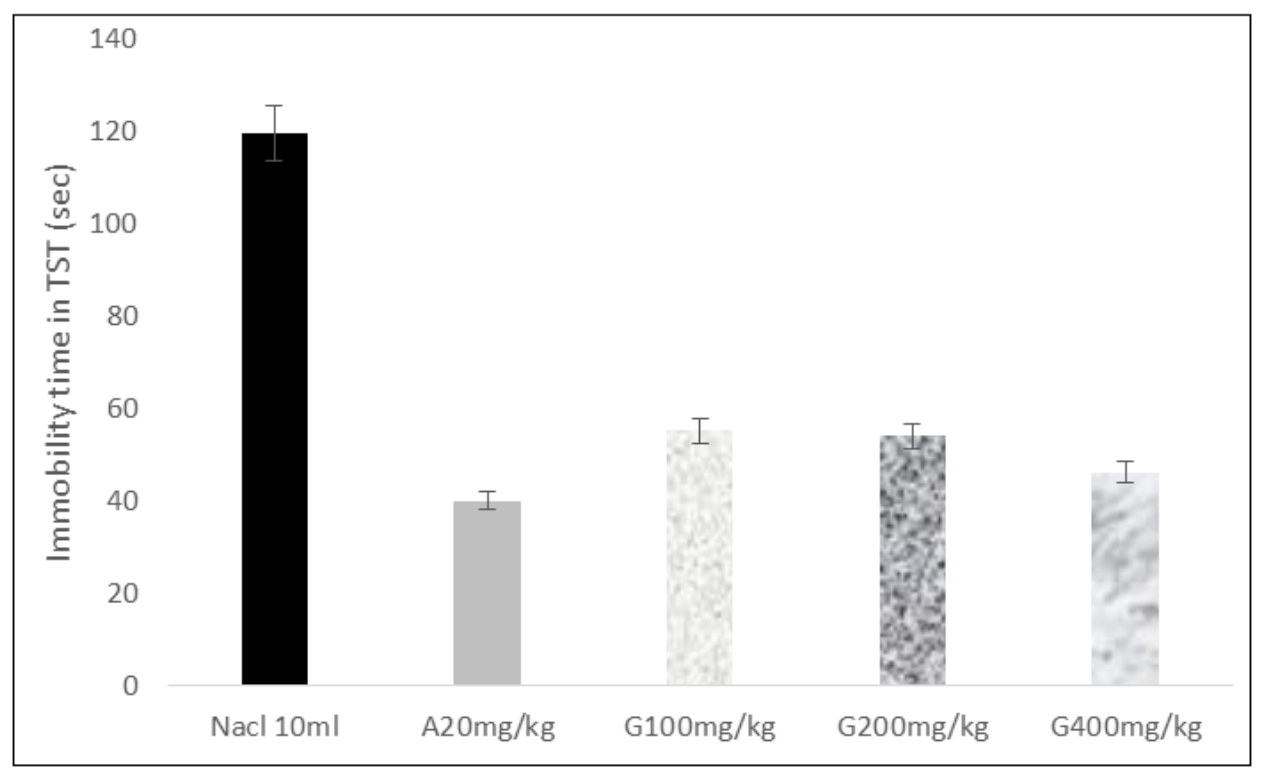

Fig-4: Effet of chronic administration of $G$. simplicifolia extract on duration of immobility in tail suspension test

Group 1: Control group (saline water); **Group 2: amitriptyline (20mg/kg); **Group 3: GS-1 (100mg/kg); **Group 4: $* *$ GS-2 $(200 \mathrm{mg} / \mathrm{kg})$; **Group 5: GS-3 $(400 \mathrm{mg} / \mathrm{kg})$. Results are represented as mean \pm standard error of mean significantly different at $* \mathrm{P}<0.05$ and $* * \mathrm{P}<0.01$ compared to vehicle control.

\section{DISCUSSION}

In our study, the significant reduction in the immobility time observed in the FST following the acute and chronic administration of $G S 200 \mathrm{mg} / \mathrm{kg}$ and $400 \mathrm{mg} / \mathrm{kg}$ suggests the antidepressant action of $G S$.
The results also showed a significant reduction in the immobility time in the TST following the acute and chronic administration of $G S 100,200$ and 400 $\mathrm{mg} / \mathrm{kg} / \mathrm{day}$. This tendency for the extract to reduce the immobility time as a function of the increase in the dose may be due to a reduction in the synthesis of 
corticosteroid hormone since the active molecules exert a predominant noradrenergic effect by increasing the climbing time and a serotonergic effect by increasing swimming time [18]. In addition [19, 20] have demonstrated that FST or TST causes corticosterone activation, increases serotonergic activity at the level of the circuit involved (tonsil, frontal cortex and hippocampus) and increases dopamine turnover. Dopamine which is involved in functions such as energy, motivation, appetite, libido, aggression, initiative, euphoria, pleasure, mood, emotions and higher functions could also potentiate its antidepressant effects [20]. In the case of aqueous $G S$ extracts, it could therefore initially be an increase in the synthesis and production of serotonin induced by 5-HTP and potentiating its effects at the level of the organism because as indicated above serotonin is involved is in several brain functions. In addition, neuropsychiatric disorders such as depression, dementia and anxiety are associated with functional abnormalities of serotonergic neurons [21]. The increase in the synthesis of serotonin could influence the synthesis of corticosterone by potentiating the negative feedback control exerted by corticosterone on the HPA axis which would thus cause a decrease in its secretion [22]. Indeed 5-HTP being the direct precursor of serotonin its administration induces an increase in synthesis of serotonin which in return acts by reducing the synthesis of corticosterone. It should be noted that it is rather plausible to refer to the reduction of immobility to the inhibition of corticosterone [23]. Indeed, it has been shown that during forced swimming, corticosteroid hormones regulate the time of immobility what Baèz and Volosin in 1994, confirm in their work by showing that an increase corticosterone was accompanied by increased immobility time during forced swimming in rats [24]. Our results are to be compared with the work of Kaur [25], who in a similar study showed the antidepressant activity of Moringa oleifera.

The results of the preliminary phytochemical analysis of G.S. seeds carried out by John Addotey [26] revealed the presence of phenolic compounds such as tannins, and flavonoids. Extracts rich in phenolic compounds have complex actions which include: inhibition of MAO-A and MAO-B, inhibition of synaptosomes of reuptake of serotonin, dopamine and norepinephrine, downregulation of receptors $\beta$ adrenergics, the positive regulation of the 5-HT2 receptor and the regulation of genes that control the function of the hypothalamic-pituitary-adrenal axis [27]. Catechins, as flavonoids found in the plant, inhibit the absorption of serotonin, dopamine and norepinephrine by synaptosomes from different regions of the brain [28]. Several investigations suggest that some minor and major depressive disorders can be ameliorated with flavonoids [29]. It has been reported that flavonoids act through their antioxidant mechanism as well as through neurogenesis.

\section{CONCLUSION}

The results obtained in this study suggest that aqueous extracts of $G S$ may possess an antidepressant activity. The preliminary pharmacological screening with acute dosing exhibited the antidepressant activity of $G S$, but its antidepressant activity was more enhanced after repeated dosing. In comparison with the acute studies, chronic dose studies displayed a significant antidepressant manifestation in the behavioral patterns when compared to the vehicle controls. This effect was far more significantly pronounced in animals treated with $G S$ at a dose of 200 and $400 \mathrm{mg} / \mathrm{kg} / \mathrm{day}$.

\section{REFERENCES}

1. Pedersen, M. E., Szewczyk, B., Stachowicz, K., Wieronska, J., Andersen, J., Stafford, G. I., ... \& Jäger, A. K. (2008). Effects of South African traditional medicine in animal models for depression. Journal ethnopharmacology, 119(3), 542-548.

2. Petkov, G., \& Ramazanov, Z. (2003). Fatty acids and sterols of Griffonia seeds oil. Grasas $y$ aceites, 54(1), 30-31.

3. Irvine, F. R. (1961). Woody Plants of Ghana. Oxford University Press; Oxford, UK.

4. Zhu-Salzman, K., Shade, R. E., Koiwa, H., Salzman, R. A., Narasimhan, M., Bressan, R. A., ... \& Murdock, L. L. (1998). Carbohydrate binding and resistance to proteolysis control insecticidal activity of Griffonia simplicifolia lectin II. Proceedings of the National Academy of Sciences, 95(25), 15123-15128.

5. Fellows, L. E., \& Bell, E. A. (1970). 5-HydroxyL-tryptophan, 5-hydroxytryptamine and Ltryptophan-5-hydroxylase in Griffonia simplicifolia. Phytochemistry, 9(11), 2389-2396.

6. Freedman, R. R. (2010) Treatment of menopausal hot flashes with 5-hydroxytryptophan. Maturitas. 65:383-385.

7. Kitahama, K., Jouvet, A., Fujimiya, M., Nagatsu, I., \& Arai, R. (2002). 5-Hydroxytryptophan (5HTP) uptake and decarboxylation in the kitten brain. Journal of neural transmission, 109(5-6), 683-689.

8. Pranzatelli, M. R., Galvan, I., \& Tailor, P. T. (1996). Human brainstem serotonin receptors: Characterization and implications for subcortical myoclonus. Clinical neuropharmacology, 19(6), 507-514.

9. Esposito, M., Precenzano, F., Sorrentino, M., Avolio, D., \& Carotenuto, M. (2015). A medical food formulation of griffonia simplicifolia/magnesium for childhood periodic syndrome therapy: an open-label study on motion sickness. Journal of medicinal food, 18(8), 916920.

10. Muszyńska, B., Łojewski, M., Rojowski, J., Opoka, W., \& Sułkowska-Ziaja, K. (2015). Natural products of relevance in the prevention 
and supportive treatment of depression. Psychiatr. Pol, 49(3), 435-453.

11. Iovieno, N., Dalton, E. D., Fava, M., \& Mischoulon, D. (2011). Second-tier natural antidepressants: review and critique. Journal of affective disorders, 130(3), 343-357.

12. Emanuele, E., Bertona, M., Minoretti, P., \& Geroldi, D. (2010). An open-label trial of L-5hydroxytryptophan in subjects with romantic stress. Neuroendocrinology Letters, 31(5), 663 666.

13. Carnevale, G., Di Viesti, V., Zavatti, M., \& Zanoli, P. (2011). Anxiolytic-like effect of Griffonia simplicifolia Baill. seed extract in rats. Phytomedicine, 18(10), 848-851.

14. Carnevale, G., Di Viesti, V., Zavatti, M., Benelli, A., \& Zanoli, P. (2010). Griffonia simplicifolia negatively affects sexual behavior in female rats. Phytomedicine, 17(12), 987-991.

15. Cryan, J. F., Markou, A., \& Lucki, I. (2002). Assessing antidepressant activity in rodents: recent developments and future needs. Trends in pharmacological sciences, 23(5), 238-245.

16. Porsolt, R. D., Le Pichon, M., \& Jalfre, M. L. (1977). Depression: a new animal model sensitive to antidepressant treatments. Nature, 266(5604), 730-732.

17. Porsolt, R. D., Bertin, A., \& Jalfre, M. J. A. I. P. (1977). Behavioral despair in mice: a primary screening test for antidepressants. Archives internationales de pharmacodynamie et de therapie, 229(2), 327-336.

18. Cryan, J. F., Mombereau, C., \& Vassout, A. (2005). The tail suspension test as a model for assessing antidepressant activity: review of pharmacological and genetic studies in mice. Neuroscience \& Biobehavioral Reviews, 29(4-5), 571-625.

19. da Silva Haeser, A., Sitta, A., Barschak, A. G., Deon, M., Barden, A. T., Schmitt, G. O., ... \& Vargas, C. R. (2007). Oxidative stress parameters in diabetic rats submitted to forced swimming test: the clonazepam effect. Brain research, 1154, 137143.

20. Connor, T. J., Kelliher, P., Harkin, A., Kelly, J. P., \& Leonard, B. E. (1999). Reboxetine attenuates forced swim test-induced behavioural and neurochemical alterations in the rat. European journal of pharmacology, 379(2-3), 125-133.

21. Collet, D. (2012). Pourquoi et de nouveaux médicaments s'implantent dans le marché de la depression: exemple des neuroleptiques, Thèse de doctorat, Université de Nantes, faculté de pharmacie, France, 125.

22. Hamon, M., \& Gozlan, H. (1993). Les récepteurs centraux de la sérotonine. Médecine Science, 9(1): 21-30.

23. Belmaker, R. H., \& Agam, G. (2008). Major depressive disorder. New England Journal of Medicine, 358: 55-68.

24. Mitchell, J. B., \& Meaney, M. J. (1991). Effects of corticosterone on response consolidation and retrieval in the forced swim test. Behavioral neuroscience, 105(6), 798-803.

25. Báez, M., \& Volosin, M. (1994). Corticosterone influences forced swim-induced immobility. Pharmacology Biochemistry and Behavior, 49(3), 729-736.

26. Kaur, G., Invally, M., Sanzagiri, R., \& Buttar, S. (2015) Evaluation of the antidepressant activity of Moringa oleifera alone and in combination with fluoxetine. Journal Ayurveda Integr Med. 6(4): 273-279.

27. John, N. A. A. (2009). Local production of 5-HTP from the seeds of griffonia simplicifolia, mémoire de master, faculté de pharmacie et science pharmaceutique, Ghana, 88.

28. Butterweck, V. (2003) Mechanism of action of St John's wort in depression: what is known? CNS Drugs, 17(8): 539-562.

29. Rocha, A. P., Carvalho, L. C., Sousa, M. A., Madeira, S. V., Sousa, P. J., Tano, T., SchiniKerth, V. B., Resende, A. C., \& Soares de Moura, R. (2007). Endothelium-dependent vasodilator effect of Euterpe oleracea Mart. (Açaí) extracts in mesenteric vascular bed of the rat. Vascular Pharmacology, 46 (2): 97-104.

30. Vauzour, D., Vafeiadou, K., Rodriguez-Mateos, A., Rendeiro, C., \& Spencer, J. P. (2008). The neuroprotective potential of flavonoids: A multiplicity of effects. Genes Nutr. 3:115-126. 